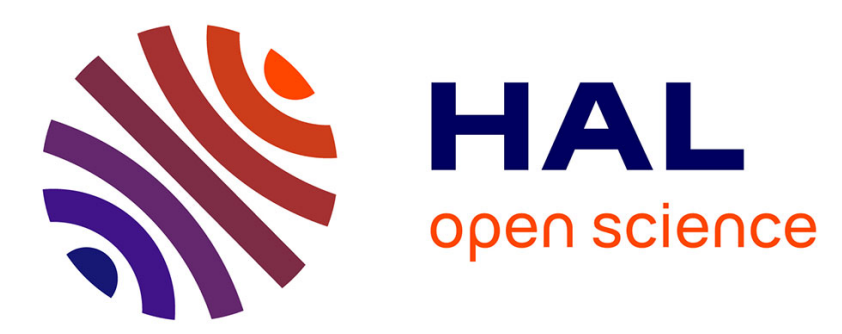

\title{
Innovative Enterprise Architectures for Deploying Product-Service Systems in SME
}

\author{
João Vilas-Boas, João Simões
}

\section{To cite this version:}

João Vilas-Boas, João Simões. Innovative Enterprise Architectures for Deploying Product-Service Systems in SME. 19th Working Conference on Virtual Enterprises (PRO-VE), Sep 2018, Cardiff,

United Kingdom. pp.637-649, 10.1007/978-3-319-99127-6_55 . hal-02191189

\section{HAL Id: hal-02191189 \\ https://hal.inria.fr/hal-02191189}

Submitted on 23 Jul 2019

HAL is a multi-disciplinary open access archive for the deposit and dissemination of scientific research documents, whether they are published or not. The documents may come from teaching and research institutions in France or abroad, or from public or private research centers.
L'archive ouverte pluridisciplinaire HAL, est destinée au dépôt et à la diffusion de documents scientifiques de niveau recherche, publiés ou non, émanant des établissements d'enseignement et de recherche français ou étrangers, des laboratoires publics ou privés. 


\title{
Innovative Enterprise Architectures for Deploying Product-Service Systems in SME
}

\author{
João Vilas-Boas ${ }^{1}$ and João Simões ${ }^{2}$ \\ ${ }^{1}$ Instituto Universitário de Lisboa (ISCTE-IUL), Business Research Unit (BRU-IUL), \\ Lisboa, Portugal \\ jmvbs@iscte-iul.pt \\ ${ }^{2}$ ROFF Consulting, Lisboa, Portugal \\ joao.rodrigues.simoes@roff.pt
}

\begin{abstract}
This exploratory research appreciates the conceptual adequateness of servitization business models for an Advanced Manufacturing Technology (AMT) SME in the Ornamental Stones (OS) cluster. It is argued for the inquiry process generated from the developed enterprise architecture (EA) as a significant research contribution to conduct fieldwork. The EA (theoretical contribution) was tested by gathering qualitative data from semi-structured interviews, unstructured observations and documentation. A discussion arose from empirical findings concerning the EA usefulness/usability to diagnose both the sponsor' state-of-the-art and needs (practitioner contribution). Primary stages of servitization found in the case might become advanced, if digital business platforms, Industry4.0 and collaborative networks (VBE/VO) are deployed. However, strong feelings of ownership in OS SME have constrained servitization progress and threatened cluster survival. Nevertheless, "mandatory" Building Information Modeling in Architecture, Engineering and Construction generates requirements for collaboration, promoting competitive advantage and enabling advanced servitization. Thus, innovative EA should anticipate/match future business requirements.
\end{abstract}

Keywords: Collaborative Networks (CN), Enterprise Architectures (EA), Servitization/Product-Service System (PSS), Business Digitalization

\section{Introduction}

Neely [1] has been considering that manufacturers should move ahead pure manufacturing and offer services and solutions, delivered through their products. Therefore, servitization is one of the key strategic choices to create differentiation from competitors by offering value-added services [2] and so, by shifting from the products sale to a Product-Service System (PSS) [3]. Servitization has been mostly adopted by large manufacturers, e.g. Rolls-Royce with the "power-by-the-hour" solution [4], despite SME importance, representing $\approx 95 \%$ of existing businesses and employing $\approx 60 \%$ of private-sector workers [5]. Thus, a first research question (RQ1) concerns the feasibility of PSS for SME, as well as for their Customers and Suppliers.

The assignment and so, all the RQ concern an AMT SME in the OS cluster, the study scope. Therefore, the PSS concern an innovative business model regarding the 
equipment supplied by an AMT SME (the study sponsor) to the OS producers. However, the move to servitization and the offer of PSS generates huge managerial challenges that many companies are not yet prepared to deal with [6]. In addition, Romero et al. [7] have been arguing for Collaborative Networked Organizations as a growing trend in a highly competitive globalized economy, where collaboration is essential for business success. Thus, the ability of SME to address such a business model (BM) might increase, if they work with partners, in a win-win Collaborative Network $(\mathrm{CN})$ relationship, since they do not appear to be prepared to deal with the consequent emerging managerial and technological challenges. Within this scope, a second research question (RQ2) arises by questioning the ability of a CN to match the challenges imposed by servitization for SME. In fact, Collaborative Organizations share core competencies and resources, for a better and quicker response to business opportunities [8].

On the other hand, Camarinha-Matos [9] also suggests that collaboration supported by Information and Communication Technology (ICT) enables SME to overcome geographic limitations and dispersion, by generating economies of scope and scale. So, a third research question (RQ3) concerns the role of ICT in the adoption of servitization and in the creation and maintenance of a $C N$.

$\mathrm{CN}$ supported by ICT appear to represent adjusted demands for the organizational structure of the research sponsor to enable the deployment of PSS business models. In fact, the sponsor is a SME with limited resources that develops Advanced Manufacturing Technology (AMT) for other SME from the Ornamental Stones (OS) Industry, being representative of the Cluster Portugal Mineral Resources Association (CPMRA). Moreover, the development of the decorative role for OS in the Architecture, Engineering and Construction (AEC) Industry has been placing new demands on the stones transformation, asking for a consumer attractive product. So, the sector leaders, which are Italian firms, compete on lower costs coming from high volumes, high product quality and, also, from their long-term reputation.

This means that the technological needs of OS SME might also be fulfilled by BM that enable customers to focus in their core business and to cut down an increasing capital investment by transferring equipment maintenance and machine update risks to the supplier. This deal become more appealing to SME, if technology customization and elimination of down times are added up, as well as their related maintenance costs, all included in a long-term pack of advanced services to be paid as a rent [10].

To sum up, this paper reports the exploratory development of a new Enterprise Architecture (EA) for a small machine tool manufacturer, based on a servitization strategy, organizationally supported by both a Collaborative Network $(\mathrm{CN})$ and a Digital Business Platform (DBP). This model is made up of propositions that are statements deducted from the literature review, which define its theoretical contents. It also includes a schematic representation depicted by using a Data Flow Diagram (DFD) to outline the design of its relationships dynamics. Put together, this provides guidance to the design of a process of inquiry to operationalize a preliminary empirical test aiming at holistically discussing the usefulness of servitization on the sponsor case study.

Next sections are, as follows: (i) Conceptual Model Definition; (ii) Methodology; (iii) Empirical Findings from the Case Study; (iv) Discussion and, (v) Conclusions. 


\section{Definition of the Conceptual Model - Theoretical Propositions}

Three propositions have arisen from an in-depth literature review. This was guided by concerns regarding the PSS feasibility for SME, the $\mathrm{CN}$ ability to fit servitization challenges and the ICT role in $\mathrm{CN}$ design, already expressed by the research questions.

Servitization stresses long term customer relationships and promotes innovation cocreation [11]. In use-oriented and result-oriented services the supplier owns the equipment, while the customer pays a long-term rent, getting rid of equipment responsibilities [12]. This enables the customer differentiation [13], supporting a sustainable competitive advantage based on a different way to deliver product functionality $[4,11]$. Moreover, setting strategic alliances is a relevant way to overcome SME resources constraints [9], being a growing phenomenon in servitization [14]. In fact, collaboration and co-innovation in services open new paths to value creation [15]. Therefore, it is concluded that PSS are feasible and desirable for SME, its Service Providers and Customers because there is a convergence of interest (Proposition 1).

Moroever, business strategy and organizational structure are mutually dependent [16]. So, the increase in SME organization complexity introduced by servitization generates new needs for the structure $[6,13]$, a requirement for organizational change [17] and different relationships with the stakeholders [6, 13], as well as the adoption of new technologies [18]. A Virtual Organization (VO), which is based on networks that describe different relationships with external stakeholders [19] apperars to be an interesting solution deserving to be detailed. A VO is a distributed, geographically dispersed, on-going, dynamic, temporary and self-restructured network of independent win-win partners supported by a common IT infrastructure that extends the internal organisation by cooperative processes facilitated by market coordination mechanisms and driven by demand, by sharing opportunities, information, cost and risk [20]. In fact, VO implementation leverages competencies, services and resources that are required to capture value, in order to overcome limits to growth imposed by rules and hierarchies [20]. In VO, the important process of partner selection might be conducted from the full population of organizations, which is not advisable, or from potential partners previously identified and prepared to collaborate that are grouped into a Virtual Organizations Breeding Environment (VBE) [21]. This is a long term association that includes an interoperable ICT, working rules and cooperation agreements, which assure the basic functioning of a $\mathrm{CN}$ [21]. To sum up, Collaborative Networks through VO and VBE fit the challenges imposed by servitization for SME (Proposition 2).

Technology is continuously changing the nature of products, processes, strategies, business models and competition [22], which might support the adoption of a PSS strategy [23] through an interoperable collaborative network. In fact, the new ICT requirements for the implementation of advanced services in servitization are illustrated by the four main topics, as follows: new ERP needs, Remote Repair Diagnostics and Maintenance Technology (RRDMT), Digital Business Platform (DBP) and Industry 4.0 (I4.0). For instance, in servitization there is a requirement for continuous data collection, treatment and processing [1] on a relational base that is out of the ERP scope (transactional). Moreover, RRDMT enable the identification and improvement of behaviour patterns that are critical to servitization, equipment remote control and repair customers needs and suppliers relationships [24]. In addition, a DBP is a common 
platform including several technologies targeting mutual development based on new digital business models that might enable SME to compete with big size companies [25]. As regards outputs, the DBP would share information concerning the PSS such as the equipment performance (e.g. availability, reliability), as well as service cost [26], linking the physical and virtual worlds.

Furthermore, an adequate EA [27] avoids ineffective strategy implementation by orienting the planning and design of IS/IT resources to match institutional objectives [28] and so, close the strategic gap [29]. In the EA context, the Business Architecture (BA) - e.g. servitization - is the strategic path used to orient the design of competitive business processes strategically aligned - e.g. VO/VBE - according to Gartner [29]. A digital platform allows a community of partners, providers and customers to share and enhance digital processes and capabilities for mutual benefit [29], which confirms DBP as an enabler of a VBE. In this way, different combinations of business models, leadership, talent, delivery and IT infrastructure platforms [29] might happen in a VBE ecosystem. Gartner [29] anticipates that $50 \%$ of BA will focus on DBP, until 2018. So, ICT through a DBP, does enable the creation and maintenance of a CN (Proposition 3.1). Moreover, by pushing and enabling the ability of two or more systems to exchange and use information among them [30] technology demands an interoperability that is essential to the servitization business model. This interoperability requirements are placed at organizational level (business objectives and processes), semantic level (digital meaning of exchanged resource) and, at technical level (technology heterogeneity) [31]. In this way, ICT is [also] an enabler of advanced services in servitization (Propostion 3.2), in addition to enable a VBE CN. Finally, it might be added that several elements of I4.0 [32] are present in the DBP. For instance, sensors, WiFi networks, and intelligent machines are generating huge amounts of data (big data) that might need to be stored in the cloud and transmitted across long distances requiring special requirements of Cyber Security. This configures an example of Industrial Internet of Things (IIoT), which might be completed by the generation of smart objects within a cyber-physical environment to enable remote monitoring and control of the production machines put together with both people and virtual/non-physical objects. To sum up, these propositions were deducted from an in depth literature review guided by the RQ, are part of the conceptual model, support the inquiry process and will be discussed with the data collected from the case study.

\section{Methodology}

This research aims at exploring the degree of fitness, adequateness and usefulness among PSS, CN and DBP, theoretically integrated as graphically depicted in Figure 1. Therefore, a hypothetical-deductive approach was pursued by deducting a conceptual model, i.e. the Enterprise Architecture (EA), from a literature review that took place ahead of the field work. This model is not to be implemented but it is a core part of the developed process of inquiring supporting its conceptual development from the literature. Therefore, three propositions aiming at empirical cross-sectional discussion were deducted. Moreover, an organized and systematic process of inquiry to approach the state-of-the-art of servitization in the investigated case study was generated from 
the EA model [33] and so, from the deducted propositions. This innovative EA model promotes the building up of a supported answer to the research questions and so, of an organized path to pursue the research purpose. Its main dimensions are, as follows: (i) graphical expression by using a DFD approach (Figure 1); (ii) detailed description of entities, activities and data flows by using a DFD approach [33]; and, (iii) generic interview guide deducted from the conceptual model description, to be customized according to each case situation [33]. This interview guide operationalizes the systematic inquiring process enabling that data to be collected match the research questions needs. Propositions will also be discussed during the research process aiming at "answering" the research questions. Its role is different from hypotheses that are quantitative and aiming at being either accepted or rejected. It is argued for this inquiring process as an innovative contribution to work into operations research.

In summary, the conceptual EA depicted in Figure 1 represents a holistic approach to express a modern and updated strategic path for AMT SME in the OS cluster that makes explicit the disruptive role of the technological push. Therefore, a strategic reply was drawn in Activity 1 by matching the contextual threats and opportunities. Then, Activity 2 characterizes the structural configuration for enabling the chosen strategy. Finally, in Activity 3 adequate updated technological solutions are proposed based on the current status-of-the-art. The identified sub-activities process information, by transforming dataflows inputs into outputs. Thus, 40 dataflows were detailed from the literature [33]. In fact, they interconnect and transport information among sub-, interand intra-activities based on the analysis of the propositions coming from an in-depth literature review. As a consequence, a supported process of inquiry was theoretically designed, ahead of the fieldwork, a sine qua non condition for a deductive research [33]. Therefore, this framework enables the AMT SME to conceptually assess the requirements for a servitization business model, by holistically projecting its strategic vision of the business in the future, as regards the strategy itself, the organizational structure and the related technological requests. In this way, AMT SME may conceptually anticipate and discuss their future needs in terms of structure, business processes and resources that might be required to support the pursuing of a strategic servitization path towards their business goals.

At last, primary data were gathered by three semi-structured interviews at the sponsor and, completed by in loco observation and secondary data. Company directors from an innovative AMT SME with close academic relationships were interviewed. The interview guide was customized based on the conceptual model [33], according to [34] advices. However, some open questions were considered, in order to enable some exploration of relevant topics not included in the guide [34, 35]. A company site visit was run to better understand the business context, as well as to collect some data both secondary from documentation analysis and primary from unstructured observations. Then, source triangulation was pursued [34]. Finally, while construct validity was coming from a thorough literature review, reliability was assured by sending to the interviewees copies of the notes, asking for their feedback and further correcting them. Since that the case study was purposefully selected, then the external validity of the results only concerns the chosen case, which is part of the CPMRA. Nevertheless, some analytical generalization [35] might even be possible, as further research. 


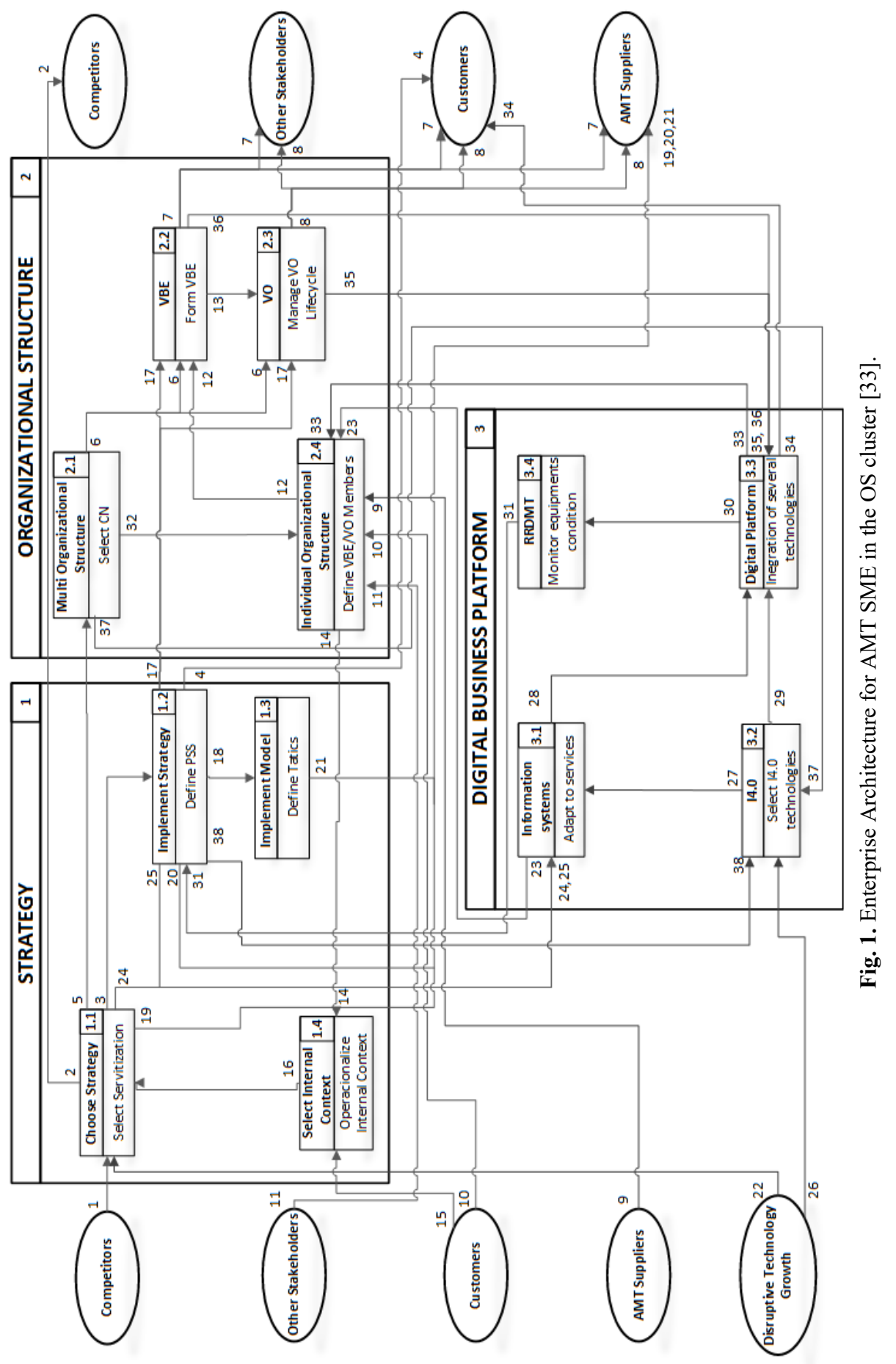




\section{Empirical Findings from the Case Study}

The case sponsor is an international AMT SME with 20 years of existence. This hidden champion provides a service that is aiming at maximizing the customer return on investment by guaranteeing that the "machines are working at peak performance levels". They accomplish this commitment through (i) an on-line remote service, (ii) a global network of a highly skilled technical support staff, and by (iii) working together with the customer to optimize system and operator performance for greater productivity and quality. The case findings will be organized according to the developed propositions in section 2, as follows.

Proposition 1: The case study firm develops horizontal technologies. It has already promoted innovation through cross-fertilization with the shoes industry, concerning the water jet cutting machines. Its main business model is oriented to product, despite a certain level of servitization having been offered as services associated to the products, as follows: 1) in sales - machine transportation, deployment on customer, customization, training and machine revision; 2) in maintenance - remote assistance during lifecycle at no cost; corrective maintenance, free for 2 years, for eliminating manufacturing defects, but paid to fix breakdowns. Despite this PSS stage being possible among SME customers, the risk is higher, because these companies, i. e. SME, are more fragile than long established big firms. However, one might still expect the AMT SME requirement for PSS to increase, depending on: the evaluation of business risk, specific marketplace demand, customer attitude towards machine use, relationships closeness, contractual conditions, customer assessment (education, training, use adequateness, maintenance concerns, etc.), geographic location, local partners typologies, etc. On the other hand, there are requirements for collaborative distributed structures (VBE) as an enabler of the implementation of Building Information Modeling (BIM) procurement, a concern that is currently being introduced in the AEC Industry (flow 11 in Figure 1). In this way, either inter-client collaboration or client/supply chain collaboration or intra-SC collaboration in the OS are facilitated by a VBE/VO, which represents a new step in the cluster towards BIM introduction, according to our source. These requirements are also expected to facilitate the introduction of PSS supported by I4.0 initiatives, on both the manufacturers (OS SME) and OS customers sides, by bringing together partners to build up collaborative partnerships to address that threat. In fact, there is a convergence of interest on collaborative networks that might serve a threefold purpose, i.e. the new business models concerning the servitization of technology (AMT SME), the focus on the core business processes leaving out complex technologies for the experts (OS SME) and the partnerships to address BIM procurement (OS SME and OS customers). To sum up, it is argued for a convergence of interest between Customers and Service Providers that leverages the desirability of PSS for SME by supporting its feasibility.

Proposition 2: The decreasing of times-to-market of technological solutions introduced at higher rates, the increasing investment costs led by technological innovation and, the increasing complexity of both solutions and technology are reasons why the case company has chosen to pursue its own development together with other partners, such as AMT suppliers, Universities, Sectorial Technological Centers, 
Sectorial Associations and Customers. These consortia were formed to address mobilizing R\&D projects, or other types of collaborative initiatives, e.g. innovative cocreation of technologies (AMT). This is the tested routing that will be used [36], once again, to reinforce the implementation of I4.0 within the context of a DBP that aims at supporting a collaborative network to enable an advanced PSS business model. In fact, challenges and requirements for this purpose are much broader, in both scope and scale, from the ones aiming at the focused development of AMT in equipment. In fact, the task is so huge that it might very well be impossible to address it as an independent firm. So, the new business model itself (servitization) will be dependent on a VBE from where VO will be formed to address the needs of a strategic Product-Service System configuration (e.g. flows 17, 13 in Figure 1). To sum up, CN not only fit the challenges of servitization in the AMT SME, but they can simultaneously serve other purposes, such as the development of broader technological solutions by generating different VO from the same VBE, e.g. BIM procurement, as one interviewee stressed.

Proposition 3: The case study firm specially highlighted the role of ICT in the adoption of advanced services in servitization in several ways, as follows: i) production - sensors, cameras and advanced proprietary software enabling digitalization and optimization of the cut profile to avoid defects and, also, to enable pattern matching; gathering production data to enable reliable production management, e.g. actual schedule, used materials, quality control, machine and operator times, set up times, down times, idle times, etc. ii) maintenance - gathering, treating and processing massive amounts of data about equipment condition (e.g. energy consumption, oil leakages, equipment performance) through sensors, augmented reality and proprietary software enable remote maintenance. This means on time, cheaper and effective service, saving on travelling expenses. Moreover, progress in maintenance can be achieved by adequate software tools exploring the relationship between prognostics \& health management technologies and, servitization [12], which might support the planning of the interventions of a $\mathrm{CN}$ of maintenance experts. The drawback concerns the "secrecy of clients' information" causing equipment to be off-line most of the time. On the other hand, data interoperability was mentioned as regards future requirements for BIM standards in procurement, despite many concerns of I4.0 already being addressed might also sustain this point. In addition, it looks that the involvement with the ICT support to $\mathrm{CN}$ (mezzo level) is not yet an institutional priority, perhaps because the company has mainly been focused in the development of advanced CNC machinery (micro level). However, it looks that is confirmed that ICT does enable the creation and maintenance of a $\mathrm{CN}$ through a DBP.

In fact, many of the current equipment features at the micro level are enablers of the digitalization required by $\mathrm{CN}$, e.g. data interoperability, big data and related patterns, remote control, remote maintenance, specific proprietary software, standard $\mathrm{CAD} / \mathrm{CAM}$ data formats, data security, real time operation, etc. So, the use of this equipment is a sine qua non condition for the deployment of $\mathrm{CN}$ (e.g. flows 35, 36, 37 in Figure 1). Moreover, there appears to be an ongoing Digital Business Platform (DBP) under development, of which value/interest might be adequate for "different" $\mathrm{CN}$, as far as their operating purposes require advanced manufacturing equipment; so, the same DBP is equally relevant to support; i) either a new PSS business model for the AMT SME; ii) or a servitization situation that enables OS manufactures to focus on their core business (OS SME); iii) or, even, a new BIM business procurement model for OS SME 
and OS customers. Therefore, despite ICT is confirmed as an enabler of advanced services in servitization, the scope of the collaboration relationship supported by these equipment features appear to reach applications and uses far beyond the strict interest on a different business model (servitization) for AMT SME. Therefore, as regards the implementation of the $\mathrm{CN}$, despite a $\mathrm{VO}$ aiming at this purpose might be formed from the emerging VBE, other VO with different purposes might also be formed (vide Figure 2). To sum up, huge synergies might be achieved without a sharp increase in complexity, since different VO will address different purposes, despite being formed from a common VBE, the supporting $\mathrm{CN}$. So, there is a requirement for an analysis at a macro level that sets the scene for a VBE in the OS, aiming at a broader purpose.

\section{Discussion and Conclusions}

The case study AMT SME belongs to the OS cluster, i.e. a set of organizations within the same specialization scope (OS), closely located, collaborating and achieving better results than isolated firms working on their own [37]. This is a different situation from belonging to a sector that is a grouping of companies put together for administrative or statistical purposes. The cluster behaves as a collaborative network constrained by a geographic area accomplishing the pre-requisites of PSS [38], since the delivery and contracting of services depend on the geographical relationship between customer and supplier [14]. On the other hand, one might conclude from Camarinha-Matos et al. [39] that the participation in a cluster in not enough for an advanced servitization strategy. In addition, Camarinha-Matos [9] refer to a VBE as a more feasible environment for service providing by being the preferable path to $\mathrm{VO}$ generation.

The major contribution of this research is the recognition of the emergence of VBE supported by DBP as relevant enterprise architectures to deploy collaborative networks as organic and flexible organizational structures that enable the development of innovative business models for SME, such as servitization (RQ2). In fact, a record of Past collaboration and good institutional relationships were found as significant enablers of a VBE (e.g. flow 12 in Figure 1), where VO dedicated to the repairing services that are required by servitization might be bred. Moreover, other different VO might come out of the very same VBE to address different needs of the cluster (vide $\S 4$ ). Therefore, the VBE is supported by a DBP (e.g. flows 23, 33 and 12 in Figure 1), which is essential for deploying PSS, as well as for developing an e-procurement strategy to implement a Building Information Modeling (BIM) approach in the AEC sector. To sum up, the empirical test of the proposed conceptual design of an Enterprise Architecture (Figure 1) shows that PSS are feasible for both a SME and remaining stakeholders involved in the collaborative relationship (RQ1).

Furthermore, emerging VO might result from the integration of cloud data, knowledge, systems and resources from several physical organizations with people into Cyber-Physical Systems (CPS), as depicted in Figure 2. Therefore, there is a requirement for AMT SME to adopt I4.0 technologies, i.e. IIoT, Big Data, Cloud Computing, etc., which demand data interoperability among partners. For instance, this could result into a cloud resident CPS (receiving information from an equipment concerning a problem) being able to automatically search the VBE for resources, put 
them together and suggest a VO aiming at solving the problem (Figure 2). In this sense, I4.0 solutions might very well be considered as a major enabler of the $\mathrm{CN}$ deployment, which provides a conceptual answer for RQ3, as depicted in Figure 2.

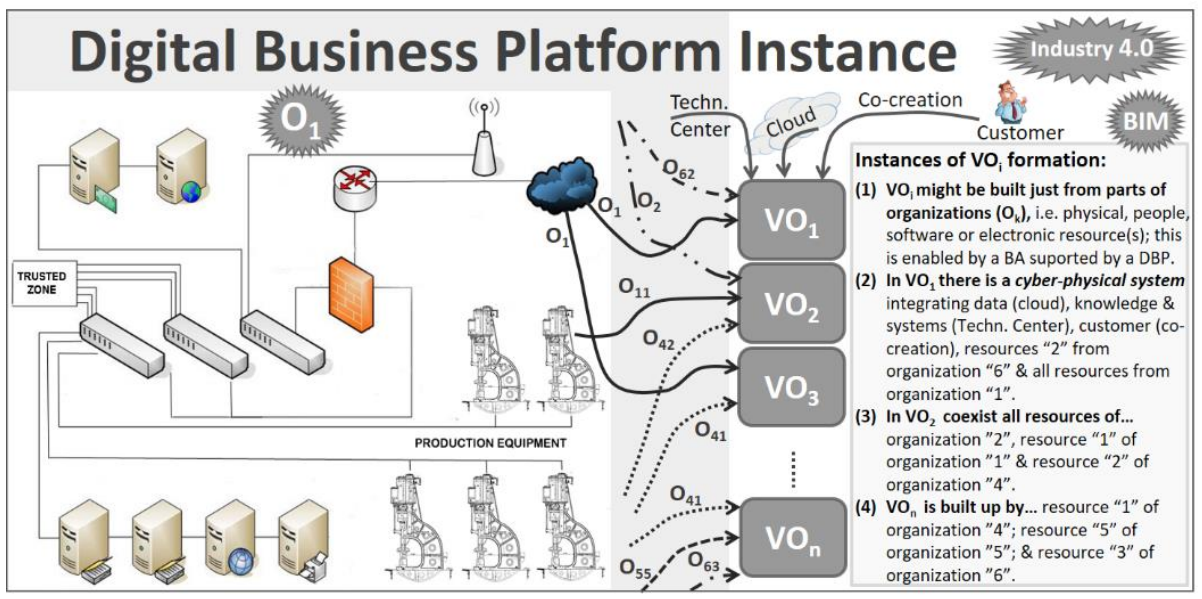

Fig. 2. Instance of a DBP supporting the formation of Virtual Organizations [36].

In summary, the developed conceptual model (Figure 1) might present an innovative contribution to theory by putting together inputs from several knowledge areas strategy, organizational structuring and IS/IT - into a useful enterprise architecture to operationalize PSS, expressed by a detailed DFD. Moreover, the used subsequent process of inquiry (vide [33] for detail) to question the state-of-the-art of real world SME illustrates a potential innovative contribution to research. Finally, this assignment, as a whole, may provide a significant innovative contribution to the practitioner, as regards the conceptual operationalization of routes to pursue the strategic objectives of a business model aiming at a servitization approach.

At last, it should be clear that the scope of this research was delimited by a conceptual approach. This is a legitimate researcher decision that was made by the start of the exercise. So, it is not a limitation to exclude the focus on implementation details or, even, on the specification of the technical solution. In addition, two significant limitations to servitization are going to be addressed next. First of all, in some markets, for some customers it might be difficult or unattractive to build up a VBE/DBP, because they miss the adequate conditions, such as the right partners or relationships, its internal social capital, money or knowledge to deal with business digitalization. This affects the offer of some advanced services of PSS. Secondly, the lack of open innovation in the OS SME generates strong feelings of ownership towards physical resources, capital, information and data that constrain collaboration and so, the progress of servitization, which might even provide a threat to the cluster survival. Therefore, hybrid business models are advisable for AMT SME looking for situational adaptation to different business contexts. Nevertheless, it should be added that "mandatory" progress towards BIM is expected in OS SME, due to the current trends in the AEC sector. This is going to generate strong requirements for $\mathrm{VBE} / \mathrm{VO}$, which will leverage competitive 
advantage and enable the servitization progress in AMT suppliers. To sum up the main recommendation for further work concerns studying a $\mathrm{CN}$ that implements a broader VBE to accommodate both current and anticipated future business requirements for the CPMRA, e.g. the INOVSTONE 4.0 initiative. Focusing on $\mathrm{CN}$ and digitalized business models might help SME to overcome both the organizational (structural, human and technical) and financial weaknesses that might constrain business development.

Acknowledgements. This research is supported by the INOVSTONE 4.0 Project, which is funded by Portugal 2020, within the scope of Programa Operacional Competitividade e Internacionalização e Programa Operacional Regional de Lisboa.

\section{References}

1. Neely, A.: The servitization of manufacturing: an analysis of global trends. In: Proceedings of 14th EurOMA, pp. 1-10. University of Ankara, Ankara, Turkey (2007)

2. Ahamed, Z., Kamoshida, A., Inohara, T.: Organizational factors to the effectiveness of implementing servitization strategy. J. Service Science \& Management. 6 (2), 177-185 (2013)

3. Baines, T., Lightfoot, H., Benedettini, O., Kay, J.: The servitization of manufacturing: A review of literature. J. Manufacturing Technology Management. 20 (5), 547-567 (2009)

4. Davies, A.: Moving base into high-value integrated solutions: A value stream approach. Industrial and Corporate Change. 13 (5), 727-756 (2004)

5. Gasiorowski-Denis, E.: The big business of small companies (2015), http://www.iso.org/iso/news.htm?refid=Ref1937. Accessed 22 May 2017

6. Oliva, R., Kallenberg, R.: Managing the transition from products to services. Int. J. Service Industry Management. 14 (2), 160-172 (2003)

7. Romero, D., Galeano, N., Molina, A.: Mechanisms for assessing and enhancing organisations' readiness for collaboration in CN. Int. J. Production Research. 17 (1), 4691- 4710 (2009)

8. Camarinha-Matos, L., Afsarmanesh, H.: Elements of a base VE infrastructure. J. Computers in Industry. 51 (2), 139-163 (2003)

9. Camarinha-Matos, L.: Collaborative networked organizations: Status and trends in manufacturing. Annual Reviews in Control journal 33 (2), 199-208 (2009)

10.Baines, T., Shi, V.: A Delphi study to explore the adoption of servitization in UK companies. Production Planning \& Control. 26 (14-15), 1171-1187 (2015)

11.Tuli, K., Kohli, A., Bharadwaj, S.: Rethinking customer solutions: From product bundles to relational processes. J. Marketing. 71 (3), 1-17 (2007)

12.Greenough, R., Grubic, T.: Modelling condition-based maintenance to deliver a service to machine tool users. Int. J. Advanced Manufacturing Technology. 52 (9), 1117-1132 (2011)

13.Gebauer, H., Friedli, T.: Behavioral implications of the transition process from products to services. Journal of Business \& Ind. Marketing. 20 (2), 70-78 (2005)

14.Baines, T.: Servitization impact study: How UK based manufacturing organisations are transforming themselves to compete through advanced services. ABS, Birmingham (2013)

15.Camarinha-Matos, L.M., Ferrada, F., Oliveira, A.I., Afsarmanesh, H.: Supporting productservicing networks. In: Proceedings of 2013 International Conference on Industrial Engineering and Systems Management (IESM), Rabat, pp. 1-7 (2013)

16.Silva, J.: Restating a research definition in conformance to soft systems semantics. In: Proceedings of 16th EurOMA Conference, Sweden, 14-17 of June (2009)

17.Bustinza, O., Bigdeli, A., Baines, T., Elliot, C.: Servitization and competitive advantage: the importance of organizational structure. Research-Tech. Management. 58 (5), 53-60 (2015) 
18.Baines, T.: Exploring service innovation and the servitization of the manufacturing firm. Research Technology Management. Sept-Oct, 9-12 (2015)

19.Reim, W., Parida, V., Ortqvist, D.: Product service systems (PSS) business models and tactics e a systematic literature review. J. Cleaner Production. 97, 61-75 (2015)

20.Silva, J., Almeida, I... Collaborative networks as incubators of dynamic virtual organizations. Int. J. Manufacturing Technology and Management. 31 (1-2-3), 192-216 (2017)

21.Afsarmanesh, H., Camarinha-Matos, L.: A Framework for management of VO breeding environments. In: Camarinha-Matos, L., Afsarmanesh, H., Ortiz, A (eds.). Collaborative networks and their breeding environments, pp. 35-48. Springer, Boston (2005)

22.Porter, M., Heppelmann, J.: How smart, connected products are transforming competition. Harvard Business Review. 92 (11), 1-23 (2014)

23.Reinartz, W., Ulaga, W.: How to sell service more profitable. HBR. 86 (5), 90-96 (2008)

24.Baines, T., Lightfoot, H.: Servitization of the manufacturing firm: Exploring the operations practices and technologies. Int. J. Operations \& Production Management. 34 (1), 2-35 (2013)

25.Manyika, J., Chui, M., Lund, S., Ramaswamy, S.: What's now and next in analytics, AI, and automation. McKinsey Global Institute (2017), http://www.mckinsey.com/globalthemes/digital-disruption/whats-now-and-next-in-analytics-ai-and-automation?cid=othereml-alt-mgi-mgi-oth-1705\&hlkid=9a6016170fcb420f8a121a17c5a33c63\&hctky=2399862 \&hdpid=8ce712f8-63e5-406f-bcdf-1cbc2c3f7d05\#Table. Accessed 22 May 2017

26.Lightfoot, H., Baines, T., Smart, P.: Examining the information and communication technologies enabling servitized manufacture. Proceedings of the Institution of Mechanical Engineers, Part B: J. Engineering Manufacture. 225 (10), 1964-1968 (2011).

27.FEAPO.: Common perspectives on enterprise architecture. Federation of EA Professional Organizations. Architecture and Governance Magazine. November, 1-12 (2013)

28.Burton, B.: Digital business architecture - From strategy to guiding execution. Gartner (2017), https://www.gartner.com/webinar/3251017. Accessed 9 May 2017

29.Gartner.: Gartner Says That by 2018, Half of EA Business Architecture Initiatives Will Focus on Defining and Enabling Digital Business Platform Strategies. Gartner Press Release (2017), http://www.gartner.com/newsroom/id/3660017. Accessed 7 April 2017

30.Geraci, A.: IEEE standard computer dictionary: Compilation of IEEE standard computer glossaries. IEEE Press (1991)

31.Pagano, P., Candela, L., Castelli, D.: Data Interoperability. Data Science J.. 12, 19-25 (2013)

32.Huxtable, J., Schaefer, D.: On servitization of the manufacturing industry in the RU. Procedia CIRP. 52, 46-51 (2016)

33.Simões, J.: Evaluation of innovative business models for SME: the servitization of the suppliers of advanced manufacturing tecnhologies for the ornamental stones cluster. MSc Thesis, Supervisor - João Vilas-Boas, IBS, ISCTE-IUL, Portugal (2017)

34.Saunders, M., Lewis, P., Thornhill, A.: Research methods, $5^{\text {a }}$ eds. Pearson, Harlow (2009)

35.Yin, R.: Case study research: Design and methods, $4^{a}$ eds. Sage Pub., Thousand Oaks (2009)

36.Silva, A., Vilas-Boas, J., Simões, J.: Definition of the mobiliser project INOVSTONE 4.0 Unpublished internal report Draft. Gestor do Inovstone 4.0 (2017)

37.Porter, M.: The five competitive forces that shape strategy. Harvard B. Review. 79-93 (2008)

38.Williams, A.: Product service systems in the automobile industry: contribution to system innovation?. J. Cleaner Production. 15 (11-12), 1093-1103 (2007)

39.Camarinha-Matos, L., Afsarmanesh, H., Ollus, M.: ECOLEAD: A holistic approach to creation and management of dynamic virtual organizations. In: Camarinha-Matos, L., Afsarmanesh, H., Ortiz, A (eds.). Collaborative networks and their breeding environments, pp. 35-48. Springer, Boston (2005) 